\title{
Careers, Incentives, and Publication Patterns of US and German (Business) Economists $^{+}$
}

\author{
Uschi Backes-Gellner ${ }^{a, *}$, Axel Schlinghoff ${ }^{b}$ \\ ${ }^{a}$ Institute for Strategy and Business Economics, University of Zurich, Plattenstrasse 14, CH-8032 Zurich, Switzerland \\ ${ }^{b}$ Wissenschafsrat, Cologne, Brohler Straße 11, D-50968 Cologne, Germany
}

Zurich, November 2004

\begin{abstract}
Research productivity is not constant over the lifetime of a researcher but fluctuates substantially and often seems to follow a typical pattern as shown firstly by Lehman $(1953,1958,1966)$ and later on by many others like Cole (1979), Dennis (1956), Kenny/Studley (1995); Oster/Hamermesh (1998) or Buchmueller/Dominitz/Hansen (1999). However, despite stable aggregate patterns there is substantial variation of research output across individuals. The aim of our paper is twofold. We try to identify systematic differences in individual research productivity and to explain them with differences in career incentives. We develop a theoretical model in which research productivity is driven by a combination of incentives to invest in skills and/or to produce output, both of which depend on institutional characteristics of the national university systems and their respective career paths. From our model we derive testable hypotheses on variations in individual research productivity profiles within and across countries. We test our implications based on a unique data set which we collected for 112 (business) economists in the US and 189 in Germany. We find that very effective incentives to publish are provided by promotion tournaments in the US as well as in Germany. In general this leads to elevated publication outputs in time periods preceding a major promotion and reduced publication productivity afterwards. But we also find striking differences between US and German researchers. Skill acquisition is more important for German researchers in the screening period since the first promotion decision is also strongly influenced by a qualification requirement, the so-called Habilitation. Also, German researchers lack a second major career step in comparison to US researchers, for whom a promotion to full professor is almost as important as the promotion to associate professor. Re-appointments in the German university system offer comparatively low gains and are thereby not enough attractive to induce a significant increase in research output . Therefore, incentives and publication productivity are highest early in the career of German researchers leveling off on a lower but decent level afterwards. For US researchers the situation is different. Their research output is not only significantly higher prior to their first appointment but also prior to a promotion to full professor, indicating that this promotion provides a second effective incentive to foster research output over a longer period of time. However, after promotion to full professor research output also levels off at a significantly lower level. To conclude, career incentives are induced by national higher education institutions and they are decisive to explain individual publication patterns and systematic differences in publication patterns of German and US researchers.
\end{abstract}

JEL Classification: M51, M52, J24, 121 Keywords: Career Incentives, Research Productivity, Publication Patterns

\footnotetext{
* Corresponding Author: Tel: +41-1-6344281, Fax: +41 16344 370. Email: backes-gellner@,isu.unizh.ch

${ }^{+}$Research support from the University of Cologne is greatfully appreciated. For comments and discussions we participants of the personnel economics workshop at Trier and Cologne, of the SASE annual conference and of the annual conference of the German Association of Business Economists. The views expressed herein and all remaining errors are those of the authors. The data used in the analysis are clearly and precisely documented and are readily available to any researcher for purposes of replication.
} 


\section{Introduction}

Research productivity is not constant over the lifetime of a researcher but fluctuates substantially and often seems to follow a typical pattern. Lehman $(1953,1958,1966)$ was among the first to systematically analyze such patterns by using cross-sectional data. $\mathrm{He}$ studied the relation between age and scientific productivity and found that a sharp increase in productivity at the beginning is followed by a decline in the later part of a researcher's career. The age of maximum output differs somewhat from discipline to discipline and is located around the age of 30 to $45 .{ }^{1}$ Furthermore, this pattern is strongest for high-quality research. Using longitudinal data, Cole (1979) and Dennis (1956) find flatter career publication patterns but the same overall pattern across many disciplines. Some recent studies confirm these results for today's economists: productivity rises at the beginning and declines towards the end of the career [Kenny/Studley (1995); Hutchinson/Zivney (1995); Oster/Hamermesh (1998); Buchmueller/Dominitz/Hansen (1999)]. According to Goodwin/Sauer (1995) the career productivity profiles of US economists are best represented by fifth grade polynomials. Looking at institutional correlates, Goodwin/Sauer (1995) and Hutchinson/Zivney (1995) find a decline in publication output of researchers after tenure has been granted, and Mahoney/Ready (1997) find that tenured economists publish fewer articles in refereed journals and proceedings than economists without tenure. Based on a sample of longitudinal data for 112 economists and business economists in the US and 189 in Germany we analyzed lifecycle publication patterns and find again very similar patterns. On average, our data show a sharp rise at the beginning of the academics' careers and a decline afterwards. But despite these very stable aggregate patterns there is substantial variation of research output across individuals. $^{2}$

Therefore, we try to answer two questions in our paper: Firstly, how can differences in individual research productivity over the lifecycle be explained, and secondly, what im-

\footnotetext{
${ }^{1}$ There are also systematic field specific patterns. According to Lehman, the maximum is reached at an earlier age in the hard sciences, and McDowell (1982) shows that career publication patterns are the flatter the faster knowledge becomes obsolete in a discipline.

${ }^{2}$ For more details see Schlinghoff 2003.
} 
pact do national institutional peculiarities have? In section 2 we introduce a theoretical model in which research productivity is driven by a combination of incentives and skills, both of which depend on institutional characteristics of the national university systems and their respective career paths. Due to the importance of varying institutional settings we test our model in an international comparison. We look at Germany with a traditional European career system for researchers and the US with its well-known tenure-based career system. Although the two systems look quite different, they still have some functional equivalents which are often overlooked but make them an ideal pair for comparison. Based on our theoretical model and the institutional details of the two countries, we derive testable hypotheses on similarities and differences in individual productivity profiles within and across countries in section 3 . These are tested in section 4 on the basis of a unique data set of 112 (business) economists in the US and 189 in Germany. Finally, in section 5, we finish with a summary and some conclusions for future research.

\section{A model of research output in the academic career lifecycle}

Past explanations of career publication patterns were mainly based on optimal investment cycles. Two different types of investments were considered separately. Firstly, researchers invest in skills and knowledge which increases their productivity in the following period [McDowell (1982)]. Secondly, researchers invest in reputation by publishing their findings. Reputation pays off later in their career by higher income opportunities [Diamond (1984; 1987); Levin and Stephan (1991)]. Both types of investments, i.e. investment in human capital and in reputation, are more profitable if they are made at the beginning of a career. Therefore, both types of explanations predict a sharp rise of publication at the beginning of a career followed by a steady decline. ${ }^{3}$ Furthermore, in a recent paper Coupé/Smeets/Warzynski (2003) show a correlation between output of economists and promotion incentives. They show that - according to tournament theory - efforts of

\footnotetext{
${ }^{3}$ There is a subtle difference. The career publication patterns predicted by investments in skills lag behind the pattern predicted by reputation. The lag is due to the amount of time needed for learning.
} 
assistant and associate professors increase with the wage spread from assistant/associate to full professorship.

In the following section 2 we present a model which incorporates both types of investments under varying incentive structures, which are driven by differences in the higher education systems and their particular institutions. This allows us to show the impact of institutional differences on the investment decisions and derive hypotheses on lifetime productivity patterns.

In our model we assume that a researcher's output depends on effort and skills. Variations of output over time are due to variations in these two variables. We further assume that productivity increases both in effort and in skills. However, skills firstly have to be acquired before they can increase productivity and thereby output. ${ }^{4}$ In the screening period, production of output is slowed down, so there is a short term cost of investment in skills which pays off only later. Thus, researchers are faced with a trade-off between investing in skills and producing output. Their decision on how much and when to spend time on either of the two activities depends on the incentives given by their institutional environment, namely the incentives in the national higher education system. In general, we assume that incentives in the university system arise from a tournament-like career system and/or from output-based pay schemes. Therefore, we use an extended tournament model to show how researchers allocate their efforts and investments over time. We further assume that winning a tournament depends on research output and credentials.

A researcher's career is divided into two periods: a screening period that ends with an upor-out tournament decision and a second period, which is the tenure period for those who win the tournament and remain in the system. Losers are employed employment outside the university system in the second period. Figure 1 illustrates the sequence of events. In the screening period, researchers either invest in skills or exert production effort. Production effort $\mathrm{e}_{1}$ produces research output $\mathrm{y}_{1}$ according to a production function $\mathrm{p}(\mathrm{e}), \mathrm{p}^{\prime}>0$, $\mathrm{p}^{\prime \prime} \leq 0$. However, research output is also affected by a random term $\mathrm{z}_{1, \mathrm{e}}$ :

\footnotetext{
${ }^{4}$ This assumption is in accordance with Baruch and Hall (2004) findings of the academic career system. They argue that a typical feature of the academic system is the practice of investing in formal education as part of the career development. Unlike in business, people in academe invest in themselves in an aim to increase their own human capital, which also includes lateral moves to create cross-functional experiences.
} 
(1) $\mathrm{y}_{1}=\mathrm{p}\left(\mathrm{e}_{1}\right)+\mathrm{z}_{1, \mathrm{e}}, \mathrm{p}^{\prime}>0 ; \mathrm{p}^{\prime \prime} \leq 0$.

Investment in skills results in a skill level $\mathrm{q}$ according to a learning function $\mathrm{g}(\mathrm{h}), \mathrm{g}^{\prime}>0$, $\mathrm{g}^{\prime \prime} \leq 0$. However, due to measurement errors $\mathrm{z}_{\mathrm{h}}$ only a biased measure $\mathrm{y}_{\mathrm{h}}$ of skills is attainable:

(2) $y_{h}=q+z_{h}=g(h)+z_{h}$

Figure 1: Timing of the Model

\begin{tabular}{|c|c|c|c|c|}
\hline $\begin{array}{l}\text { Researcher de- } \\
\text { cides on } e_{1} \text { and } h\end{array}$ & $\begin{array}{l}\text { Realization of } \\
y_{1} \text { and } y_{h}\end{array}$ & $\begin{array}{l}\text { if } y>\bar{y}: \text { pro- } \\
\text { motion }\end{array}$ & $\begin{array}{l}\text { Researcher } \\
\text { decides on } \mathrm{e}_{2}\end{array}$ & $\begin{array}{l}\text { Income } \\
\text { if promoted: } G+\beta y_{2} \\
\text { if not promoted: } V\end{array}$ \\
\hline
\end{tabular}

Research output in the second period depends on production effort $\mathrm{e}_{2}$ and skills $\mathrm{q}$ acquired in the first period. Research output in period 2 is also affected by a random term $\mathrm{Z}_{2, \mathrm{e}}:$

(3) $y_{2}=p_{2}\left(e_{2}, q\right)+z_{2, e}$.

Since production effort and investments are not observable in both periods and are affected by random components, contracts can not be based on production effort or investment effort. The usual moral hazard problem arises: Without any incentives, researchers as selfish agents ${ }^{5}$ and maximize their own utility and choose inefficiently low levels of production and/or investment efforts. Since departments or universities as principals want their agents to choose efficient levels of effort, i.e. efforts balancing marginal costs and marginal outputs, they implement particular incentive structures. Within the screening period, incentives are provided by tournaments. Only the most productive and/or best

\footnotetext{
${ }^{5}$ In a detailed analysis of the major characteristics of academic career systems worldwide, Baruch and Hall (2004) also typify an academic as "a free agent" who can move his or her career and research agenda fairly easily from one university to another in order to make career progress. They further conclude that professors are much more committed to their profession than to their organization, which is nothing else than what economists mean by moral hazard or opportunistic behaviour.
} 
qualified researchers are granted tenure. ${ }^{6}$ In the second period, after tenure has been granted, incentives are provided by some type of output-based pay.

So $\mathrm{W}_{2}$ is a researcher's income in the tenured period:

(4) $\mathrm{w}_{2}=\mathrm{G}+\beta \mathrm{y}_{2}, 0 \leq \beta$,

where $G$ is a senior researcher's base salary and $\beta y_{2}$ is the output-based pay component. Researchers who are not granted tenure after the screening period leave the system ${ }^{7}$ and receive an income $\mathrm{V}$ from an alternative job, $\mathrm{V}<\mathrm{G}$.

Thus, the pay structure in the second period is

(5) $w_{2}= \begin{cases}G+\beta y_{2}, & \text { if appointed to a tenured position } \\ V, & \text { if not appointed to a tenured position. }\end{cases}$

The relative performance measure that is used to determine the winner of the tournament is a weighted combination of the research output that is observed during the screening period and the observable qualification indicators a person received during the screening period. ${ }^{8}$ Research output can be measured by publications in journals (weighted or not) or by citations. Qualifications are measured by the credentials a person obtains, which - in the German case - is mainly the so-called "Habilitation", a formal requirement to enter a lifetime position as a professor at a German university. So the combined performance measure of research output and qualification looks as follows

\footnotetext{
${ }^{6}$ Based on an extensive study of academic career systems, Peiperl and Baruch (1997) emphasize the importance of merit rather than time on the job for the academic promotion system. Unlike in classical bureaucracies or even in private industry where time on the job plays a more important role, in academe promotion depends on performance and the "standard" measure used is publication output. Baruch and Hall (2004) even argue that "academe came long before other sectors in focusing on results and outcomes rather than tenure" (p.251).

${ }^{7}$ Although it is argued that unlike in the business sector, career paths in the academic sector are multidirectional, i.e. with movements up and down the hierarchy, we neglect this aspect in our analysis because downward movements have still been the rare exception in the past.

${ }^{8}$ Standard human capital theory states that an employee will invest in general skills. Thus, we have to answer why a principal will provide incentives for acquiring general skills like research methods in tournaments. However, standard human capital theory assumes that an employee will fully benefit from returns on human capital investments. But most times, research output is a public good. Researchers can not privatize their returns on investments. To realize an efficient level of investments in the presence of positive spill-overs, investments in human capital must be subsidized [Weisbrod (1964)]. Because investment levels can not be agreed on by contract, we explore investment incentives in a tournament structure.
} 
(6) $\mathrm{y}=\alpha \mathrm{y}_{1}+(1-\alpha) \mathrm{y}_{\mathrm{h}}, \alpha \in[0 ; 1]$

Research output is weighted by $\alpha$ and qualifications are weighted by $(1-\alpha)$. Researchers are granted tenure (hired for a tenured position) if their performance y exceeds their competitors' performance $\bar{y}$.

On the other hand there are costs to production and investment efforts. In the screening period costs are twofold: the cost of production effort and the cost of skill investment effort:

(7) $\mathrm{C}_{1}=\mathrm{C}\left(\mathrm{e}_{1}+\mathrm{h}\right), \mathrm{C}^{\prime}>0, \mathrm{C}^{\prime \prime}>0$.

In the tenured period, the researchers' costs only depend on their production effort, i.e.

(8) $\mathrm{C}_{2}=\mathrm{C}\left(\mathrm{e}_{2}\right)$.

Neglecting time preferences and discount rates, lifetime income amounts to

(9) $\mathrm{L}=\mathrm{V}+\mathrm{P}\left(\mathrm{e}_{1}, \mathrm{~h}\right)\left(\mathrm{G}+\beta \mathrm{p}_{2}\left(\mathrm{e}_{2}, \mathrm{q}\right)-\mathrm{V}\right)+\mathrm{w}_{1}-\mathrm{C}\left(\mathrm{e}_{1}+\mathrm{h}\right)-\mathrm{P}\left(\mathrm{e}_{1}, \mathrm{~h}\right) \mathrm{C}\left(\mathrm{e}_{2}\right)$,

where $\mathrm{w}_{1}$ is a fixed wage in the screening period and

(10) $\mathrm{P}\left(\mathrm{e}_{\mathrm{l}}, \mathrm{h}\right)=\operatorname{Pr}\left[\left(\alpha \mathrm{y}_{\mathrm{e}}+(1-\alpha) \mathrm{y}_{\mathrm{h}}\right)>\left(\alpha \overline{\mathrm{y}}_{\mathrm{e}}+(1-\alpha) \overline{\mathrm{y}}_{\mathrm{h}}\right)\right]$

is the probability of winning the tournament.

Risk-neutral researchers maximize their lifetime income by choosing levels of $\mathrm{e}_{1}, \mathrm{~h}$ and $\mathrm{e}_{2}$. We solve the maximization problem by backward induction (figure 1). If researchers are granted a tenured position they have to choose an effort level $\mathrm{e}_{2}$ given the wage scheme (4), second period's costs and skills q. The first order condition for optimal effort in the tenured period is:

(11) $\beta \frac{\partial \mathrm{p}}{\partial \mathrm{e}_{2}}=\mathrm{C}^{\prime}\left(\mathrm{e}_{2}\right)$.

Effort increases in $\beta$ and in the researcher's marginal productivity $\frac{\partial \mathrm{p}}{\partial \mathrm{e}_{2}}$. By definition, productivity is a strictly monotonic increasing function in skill level. Thus, second period effort is an implicit function of investments in the first period. We can show that 
$\frac{\mathrm{de}_{2}}{\mathrm{dh}}>0,{ }^{9}$ i.e. production effort in the tenured period increases with investments in the preceding period. ${ }^{10}$ Thus, investments have two impacts on research output in the tenured period. Firstly, a direct effect, i.e. investments in skills, making researchers more productive by increasing output productivity at a given effort level. Secondly, an indirect effect: investments in skills induce researchers to choose higher levels of effort in order to secure their returns on human capital investments. Applying the implicit function theorem, output in the tenured period can be written as

(12) $y_{2}=\hat{p}(h)+z_{2, e}$.

Given the optimal decision in the tenured period, we can now analyze the decision problem in the screening period. We substitute (12) into (9) and obtain the following first order conditions for homogenous agents

(13) $\alpha p^{\prime}\left(e_{1}\right) f(0)(G+\beta \hat{p}(h)-V)=C^{\prime}\left(e_{1}+h\right)$, and

(14) $(1-\alpha) g^{\prime}(h) f(0)(G+\beta \hat{p}(h)-V)+0.5 \beta \frac{d \hat{p}}{d h}=C^{\prime}\left(e_{1}+h\right)$.

Production effort and investment effort are determined by equations (13) and (14). The sum of production and investment effort increases in the wage spread, $G-V$, and in incentive intensity $\beta$. An increase in $\beta$ acts like an indirect increase in the wage spread because of improved income opportunities in the tenured period. Let $\mathrm{f}(\mathrm{z}), \mathrm{z}=\alpha\left(\mathrm{z}_{1, \mathrm{e}}-\overline{\mathrm{z}}_{1, \mathrm{e}}\right)+$ $(1-\alpha)\left(z_{h}-\bar{z}_{h}\right)$, be the joint density function of all random components. Then $f(0)$ indicates how well a researcher can influence the probability of winning the tournament by exerting production effort or by investing in skills. If $f(0)$ is small, luck is dominant in determining the winner of the tournament. In this case, the tournament does not provide strong incentives. If $\mathrm{f}(0)$ is large, luck has only little impact on winning, so the tourna-

\footnotetext{
${ }^{9}$ Schlinghoff 2003.

${ }^{10}$ If effort $e_{2}$ and human capital $g(h)$ are complementary inputs in the second period's production, then $\frac{\partial^{2} \mathrm{p}}{\partial \mathrm{e}_{2} \partial \mathrm{g}(\mathrm{h})}$ holds. Total differentiation of (11) with respect to $\mathrm{h}$ and $\mathrm{e}_{2}$ yields $\beta \frac{\partial^{2} p}{\partial e_{2}^{2}} d e_{2}+\beta \frac{\partial^{2} p}{\partial e_{2} \partial g(h)} g(h)^{\prime} d h=C^{\prime \prime}\left(e_{2}\right) d e_{2}$. Thus $\frac{d e_{2}}{d h}=\frac{\frac{\partial^{2} p}{\partial e_{2} \partial g(h)} g^{\prime}(h)}{C^{\prime \prime}\left(e_{2}\right) / \beta-\frac{\partial^{2} p}{\partial e_{2}^{2}}}>0$.
} 
ment provides higher incentives. ${ }^{11}$ Furthermore, as shown by Gibbs (2001), $\mathrm{f}(0)$ depends on the ratio of participants to the number of winners in the tournament.

Substituting (13) into (14) yields

$$
(1-\alpha) g^{\prime}(h) f(0)(G+\beta \hat{p}(h)-V)+0.5 \beta \frac{d \hat{p}}{d h}=\alpha p^{\prime}\left(e_{1}\right) f(0)(G+\beta \hat{p}(h)-V)
$$

Accordingly, we are able to derive three implications on the trade off between production effort and investment effort from our model:

\section{Fixed pay $G$ in the tenured position:}

If we assume that research output is more important than credentials for winning the tournament, i.e.

(16) $\alpha p^{\prime}\left(e_{1}\right)>(1-\alpha) g^{\prime}(h)$,

then production effort increases in relation to investment effort if fixed pay G increases. ${ }^{12}$ The intuition is that the wage spread $\mathrm{G}-\mathrm{V}$ can only be gained by winning the tournament and, according to (16), it is easier to win the tournament by exerting higher production efforts rather than by additional investments in skills.

\section{Variable pay $\beta$ in the tenured period:}

A rise in $\beta$ has two effects. First, a rise in $\beta$ implies a larger wage spread, inducing the researcher to increase production effort relative to investment effort (like in the previous case). However, an increase in $\beta$ leads to higher pay per output according to (12) and (4), which makes investing in skills in the first period more attractive because it allows producing higher output later on in the career.

\section{Relative weight of output and qualification in the tournament decision:}

If the weight of research output $\alpha$ increases in the tenure decision, production effort in relation to investment effort increases in the screening period.

\footnotetext{
11 These implications are fully compatible with the implications of standard tournament theory. If we set $\alpha=1$ and $\beta=0$ our tournament structure perfectly matches the standard tournament of Lazear and Rosen (1981).

${ }^{12}$ If $\alpha p^{\prime}\left(e_{1}\right) \leq(1-\alpha) g^{\prime}(h)$ researchers always prefer investments in the first period over production of output (reputation) because of their additional returns in the tenured period.
} 


\section{Hypotheses}

Summarizing the results of our model yields three hypotheses on how the trade-off between production effort and investment effort in the screening period is determined. The trade-off is determined by three factors: the wage spread $\mathrm{G}-\mathrm{V}$, the second period incentive intensity $\beta$ and the importance of research output $\alpha$ in relation to credentials for the tenure decision. However, we cannot make any predictions on the absolute level of production or investment effort, but only on the relative effort of production and investment effort in the first and second period. This is sufficient for our research question, though, because we only want to explain variations in the shape of career publication patterns rather than their absolute level. Given the three hypotheses that we derived from our theoretical model we expect the following shapes of career publication patterns depending on the institutional incentives within a particular higher education system.

Firstly, the higher the wage spread between tenured and untenured positions, the higher the research output in the screening period in relation to the tenured period. Secondly, the larger the incentive intensity in the tenured period, the lower is the research output in the screening period in relation to the tenured period. Thirdly, the higher the weight of research output in relation to the weight of credentials for the promotion decision, the higher is the research output in the screening period in relation to the tenured period.

In the next section we will apply these theoretical considerations to the incentive structure given by the typical career paths for German and US professors. Thereby, we obtain empirically testable hypotheses on comparative productivity profiles of US and German researchers.

\section{Institutional Incentives: the German and US University Ca-}

\section{reer Systems}

As we have shown in our theoretical analysis, differences in the wage spread (i.e. wage gains from one step of the promotion tournament to the next step), the decision criteria (relative weight of research output) and the output based pay of researchers cause systematic differences in lifetime productivity profiles. In order to test our model we therefore have to study career and pay systems that differ in these respects, in order to see 
whether the predicted differences in productivity profiles occur as predicted. We take two sets of institutional settings for academic research, namely the US and German university systems. First we give an overview on the similarities and differences in the fundamental characteristics of the two university systems. We then study in more detail the career incentives and the pay for performance incentives in both systems to derive testable hypotheses on similarities or differences in lifecycle productivity profiles of US and German economists. ${ }^{13}$

\subsection{General characteristics of the German and US University System}

Despite some major differences in the regulatory framework of German and US universities, there are many functionally equivalent institutions and regulations as we will explain in more detail below. This is very important for our study because only the similarities in the overall structure of the career systems make them suitable for a comparison of the impact of career differences. In contrast, the French career system, for example, with its universities and Grandes Écoles on one side and the CNRS - Centre National de la Recherche Scientifique - on the other side, is quite different from the US and the German system. ${ }^{14}$ Thus, taking data from the French academic system without taking into account these fundamental differences resulting from legal, historical or institutional backgrounds, would very likely only lead to statistical artifacts. ${ }^{15}$ So we have to concentrate on university systems that are functionally equivalent in their general structure. At the same time there has to be enough variation in the academic career system in order to be able to study the impact of career differences on publication productivity profiles. Therefore, we chose to analyze the US and the Germany because their respective academic career systems allow us to study the impact of well specified differences in the career systems on individual productivity.

\footnotetext{
${ }^{13}$ Further details on the economics profession are given by Coupé (2004a).

${ }^{14}$ For more details see for example Altman and Bournois (2004).

${ }^{15}$ A similar argument is made by Stryker (2003), who argues that unless socioeconomists focus on law (...) they will fail to adequately understand capitalist democracies.
} 


\section{Common characteristics of the academic career system}

In their classic study of the academic marketplace and particularly the academic careers, Caplow and McGee (1958) concluded already that the core characteristic of the academic career system is the so called vacancy-and-replacement mechanism. They consider this process, by which a department replaces its members, as central to the understanding of any academic institution. In their study they extensively analyze the inner workings of the governance mechanisms within a department, and Baruch and Hall (2004) conclude that the mechanisms Caplow and Mc Gee revealed in the late 1950s, still sound familiar and valid in today's environment. Caplow and Mc Gee also describe the "nitty-gritty" details of the evaluation process, the kinds of credentials that were used and the important role of peer review and reputational measures for a career decision. Since reputation or prestige is determined in a very early stage of the career (mainly by number of citations and high-quality publications, which themselves are a function of the resources provided by a young researcher's home institution and its prestige), Caplow and McGee conclude that an academic's career is more or less set by the age of 40 . This is consistent with the assumptions in our theoretical model whereby the first career step is characterized as a screening and investment period and the second period is an investment pay off period. ${ }^{16}$ Baruch and Hall (2004) further argue that one important characteristic of career advancement in the academic sector in any country is that firstly, promotion is subject to performance (e.g. publications) rather than experience, and secondly, career advancements are self-initiated" (p. 248). ${ }^{17}$ Furthermore, university systems are typically characterized by flat hierarchies, usually consisting of three steps that typically make advance-

\footnotetext{
${ }^{16}$ Although there are substantial changes in the academic profession due to a rapid extension and new information systems, the decision-making process itself has not substantially changed. Baruch and Hall (2004) find that "the judgement process, decisions about who participates in the hiring process, and the inter-unit negotiations within the university would all be quite familiar to Caplow and McGee" (p. 247). ${ }^{17}$ Taylor (1999) particularly emphasizes the global nature of the academic market, where researchers worldwide use a set of signals for their career aspirations. He also argues that these signals are built on reputation both of the individual/professional and institutional type. Baruch and Hall (2004) nowadays consider the concept of tenure to be a significant part of academic lives throughout the world. See also Baruch/Peiperl (2000).
} 
ment a "non-issue after the person (...) attained senior rank" (p. 248). ${ }^{18}$ This again is a very important aspect for our study since it has major consequences for the incentive intensity in the course of a typical academic's career. It means that after having attained this last step in quite an early stage or age, there are no more incentives to exert high effort. $^{19}$

\section{Differences in the academic career systems of Germany and the US}

Despite the above mentioned similarities of academic career systems in general and those in Germany and the USA in particular, there are also substantial differences between the two systems. The higher education system in the US functions without centrally established standards. It contains several thousand public and private institutions. There is a strong focus on elite and excellence, rather than on assuring common minimum standards of quality like in Germany. The US system is very hierarchical and serves multiple functions which are reflected in the shifting balance between research and teaching on undergraduate, graduate and post-graduate level. The German university system in contrast, is almost solely government funded and is based on the principle of equality of opportunities rather than on differentiation. In consequence, it is largely centralized and homogeneous [Adams (2002)] and the number of universities is much smaller in Germany. These differences have to be kept in mind when analyzing in more detail the career incentives in Germany and the US.

\footnotetext{
${ }^{18}$ Baruch and Hall (2004: 248) even argue that "there is nothing the world today, in any institutions, that approaches the level of security that is enjoyed by a tenured professor".

${ }^{19}$ However, they also argue that since the 1990s the system is changing, with part-time and adjunct positions being one of the most important new characteristics of the system. As an example for a substantially new feature within the system they mention the so called "alternative tenure track" system of Boston University, where faculty can decide on two types of tenure track at the beginning of their career: the traditional track with tenure after six successful years, and the alternative track with a probationary tenure after six successful years, that has to be renewed after another ten successful years with a higher level of compensation (10-20\%) in exchange for their higher risk [Baruch and Hall (2004)].
} 


\subsection{Career Incentives in the German System ${ }^{20}$}

In Germany, unlike in the US, a doctoral dissertation used to be only the second last step towards a researcher's career. ${ }^{21}$ Students who intend to follow a university career usually stay at their doctoral institution and are typically full time employed as senior assistants (Hochschulassistent). ${ }^{22}$ This is a temporary position with a maximum length of six years and no option to stay longer or even receive tenure. The assistant is assigned to a professor and teaches and works on research projects in consent with the professor. ${ }^{23}$

\footnotetext{
${ }^{20}$ Note however, that a recent amendment of the Higher Education Act (2002) proposes significant changes concerning the career paths of researchers at German universities and that the federal court turned down the amendment in July 2004. So our analysis may not be valid into the future, but it correctly describes the situation before 2002 since our publication data are all from the period before the new law was passed. Therefore, we restrict our institutional description to the old institutional rules.

${ }^{21}$ In this context it is worth mentioning that the majority of students who finish their doctoral degrees do not stay within the university system but leave the university system and work in private industry or in the public service sector. Thus, the doctoral dissertation is not a pure academic education but rather an advanced labor market and academic education.

${ }^{22}$ For a full description of the German Higher Education system cf. Ehlert and Cordier (2002).

${ }^{23}$ There are only very few exceptions to this rule, like writing on a Habilitation while receiving a research grant, but they are very rare and therefore not likely to be decisive in the career decision we are interested here.
} 
During these six years the young researcher is expected to write a second thesis, the so called Habilitation ${ }^{24}$, which is a requirement to apply for a regular professorship. However, the young researcher must not apply for a professorship at the degree-granting institution. After finishing the Habilitation, the young researcher is on the job market competing in recruitment tournaments. All candidates that are on the market for a particular position at a given time are ranked by an internal recruiting committee according to their quality, and the job is offered to the first ranked candidate. If he or she accepts the job offer, he/she is granted tenure and receives an income according to an income scale that is fixed by law on a national level. German professors are lifetime civil servants, they cannot be laid off and their pension is completely taken care of by the state (according to a generously defined benefit plan). On the other hand, candidates who keep failing to win a recruitment tournament will have to look for employment opportunities outside the university system, which are rare and much less attractive because job applicants with a Habilitation are often considered to be overqualified for "regular" jobs on the external labour market. Therefore, losers of the first recruitment tournament often cannot expect a significant wage increase but will more likely even have to accept a decline in wage because of their over-qualification.

For those who win the tournament and receive a "call", the new job offers either a $\mathrm{C} 3$ or a $\mathrm{C} 4$ professorship position and the income is determined by the so-called C-scale (cf. table 1). The $\mathrm{C}$-scale not only fixes the starting salary but also the salary increases, which are strictly tied to age and seniority, unless a researcher receives an outside job offer. In case of an outside job offer she can renegotiate the contract within fixed limits.

Assistants are assigned to C1, which is about 2'500 EURO per month for the youngest age group. Total pay of C3 positions starts at about 2'800 EURO per month and that of C4 positions at about 3'500 EURO per month (if they are still in the youngest age/seniority group; see table 1 for base salaries in different ranks). The salary increase of

\footnotetext{
${ }^{24}$ The Habilitation is supposed to cover a different subject than the doctoral dissertation. It is supposed to prove that the candidate is able to cover more or less the whole field, i.e. of economics or business economics. After successful completion of the Habilitation the candidate is granted the so called venia legendi for her field, i.e. the permission to teach economics or business economics. An overview of all credentials offered in the German university system is given in Danesy (1994), 35ff.
} 
a typical young researcher, who had been employed as an assistant with $\mathrm{C} 1$ salary in her previous position and is then appointed to a $\mathrm{C} 4$ professorship for the first time, amounts to approximately 1'500 EURO per month. Income increases following renegotiations due to outside job offers later in a career are usually smaller. There is a strict upper limit for renegotiating a contract to ward off an outside offer, amounting to around 600 EURO per month if the outside offer is a position within the German university system [Hartmer (1997)]. However, if the outside offer is from a foreign university or the private sector, the upper limit is substantially higher at around 3'552 EURO [Hartmer (1997)]. In addition to the monetary gains of winning the first recruitment tournament, the newly appointed professor also gains additional reputation and power, making it even more attractive to win the tournament. So the short term monetary gains of winning a first recruitment tournament are quite substantial, whereas the options for further gains in subsequent tournaments are comparably small, at least so in the single tournament rounds.

\section{Table 1: Monthly base salaries of researchers at German universities in EURO}

\begin{tabular}{lllll}
\hline Level of seniority & C1 & C2 & C3 & C4 \\
\hline 1 & 2521,57 & 2527,09 & 2782,76 & 3534,85 \\
2 & 2610,10 & 2668,18 & 2942,52 & 3720,98 \\
3 & 2698,63 & 2809,27 & 3102,26 & 3856,01 \\
4 & 2787,16 & 2950,36 & 3262,01 & 4016,61 \\
5 & 2875,69 & 3091,44 & 3421,76 & 4177,20 \\
6 & 2964,22 & 3232,53 & 3581,51 & 4337,78 \\
7 & 3052,74 & 3373,62 & 3741,26 & 4498,37 \\
8 & 3141,28 & 3514,71 & 3901,01 & 4658,95 \\
9 & 3229,81 & 3655,79 & 4060,76 & 4819,54 \\
10 & 3318,34 & 3796,88 & 4220,52 & 4980,12 \\
11 & 3406,87 & 3937,96 & 4380,26 & 5140,72 \\
12 & 3495,40 & 4079,05 & 4540,01 & 5300,28 \\
13 & 3583,92 & 4220,13 & 4699,76 & 5461,89 \\
14 & 3672,45 & 4361,22 & 4859,51 & 5607,13 \\
15 & 0 & 4502,31 & 5019,26 & 5783,06 \\
\hline
\end{tabular}

Note: Data are from www.uni-tuebingen.de/uni/qqp/Besoldung.html. 


\subsection{Career Incentives in the US System}

In order to compare the career incentives for $\mathrm{US}^{25}$ and German university researchers we have to look for functional equivalents in the careers of researchers in the two countries. The first step towards a career as a researcher in the German system is the position of assistant, which is functionally equivalent to the position of an assistant professor in the US system. Both German assistants and US assistant professors hold a doctoral degree or $\mathrm{PhD}$. In addition, both are employed on a temporary basis for about six years. The subsequent career step is a lifetime employment in academe, namely a tenured position in the US. However, there is one major difference. Assistant professors in the US are autonomous in teaching and research, whereas German assistants are still advised by tenured professors. Like in Germany, wages of US professors depend heavily on ranks. Table 2 shows average wages of US researchers by rank and the Carnegie Classification of the employing university. Other than the German system, where there is one dominant career step from assistant to full professor, the US system knows two major steps. The first is from assistant professor to associate professor with a large increase in employment security because it is tenured but a rather modest increase in income. ${ }^{26}$ The second step is from associate professor to full professor with a larger increase in income, particularly at research universities. In addition to the monetary gains, young researchers also gain reputation if promoted from assistant to associate professor and they gain even more reputation if promoted to full professor or even to a distinguished chair.

\footnotetext{
${ }^{25}$ The whole US higher education system is much less regulated than the German system, however. Even though Trow (1993) argues that the American post-secondary education is uncoordinated from the centre and without national standards for (...) the appointment of academic staff, or the rewarding of degrees, we still try to describe broad commonalities which only slightly vary between different types of universities or from state to state, etc.

${ }^{26}$ In nearly all cases of our data set, receiving tenure goes along with the promotion to the associate rank.
} 
Table 2: Salaries of researchers at US universities in US Dollars per year

\begin{tabular}{lcc}
\hline & Public & Private \\
\hline Doctoral Institutions & & \\
\hline Full & 82535 & 103761 \\
Associate & 58741 & 67661 \\
Assistant & 49100 & 58577 \\
\hline Comprehensive Institutions & & \\
\hline Full & 66657 & 71547 \\
Associate & 53143 & 55384 \\
Assistant & 43361 & 44836 \\
\hline Baccalaureate Institutions & & \\
\hline Full & 60446 & 70528 \\
Associate & 49686 & 52137 \\
Assistant & 41472 & 42819 \\
\hline
\end{tabular}

Note: Data are from http://www.chronicle.com/stats/aaup.

So the short term gains of winning the first recruitment tournament from assistant to associate professor are substantial in terms of employment security, but not so much in terms of monetary gains or reputation. At the same time, the options for further gains in subsequent tournaments in terms of income increase or reputation establishment are relatively high when compared with the German system. If we translate these institutional differences into terms of tournament theory, we will find both similarities and differences in the prize structure for US and German researchers.

Firstly, in both countries, there is an extraordinarily large winner's prize for winning the first round of the tournament due to becoming tenured, which is the all dominant factor in the first step. The incentives are therefore basically identical in the German and the US system. In both countries we expect similar and substantial efforts to produce research output while being assistant/associate professor, and a decline in effort after the first promotion due to comparatively lower potential gains in the following tournaments.

Secondly, the prize structure in the US and Germany differs systematically in the subsequent rounds of the tournament. As described in the previous paragraph, a promotion to full professorship in the US bears higher income and reputation gains than a second or third call in Germany. We expect the prospect of being promoted to full professor in the US to create higher incentives than the prospect of receiving a second or third call in Germany. Therefore, effort should be higher for a US associate professor competing for full professorship than for a German professor competing for a second or third call. Re- 
spectively, the decline in effort after becoming a full professor should be higher in the US than after a second or third call in Germany.

\subsection{Promotion decision criteria}

As described in the previous section, the most important criterion to become appointed as a tenured professor in Germany is a qualification criterion, namely the Habilitation. It consists of a thesis and an oral colloquium on a subject which must not be the same subject as the Habilitation (which is chosen on short notice by a committee out of a list of three subjects, all of which must not be related to the Habilitation). Therefore, the German system places high emphasis on a broad range of skills that a young researcher has to acquire before he or she is granted his/her Habilitation. This is the drop-out criterion of the first round of the tournament. In addition, it has been shown that the probability of becoming appointed to a tenured professorship in Germany increases with the number of publications [cf. Schlinghoff (2002)], but it is still subject to having finished the Habilitation in the first place.

On the contrary, the single most important criterion for the tenure decision in the US system is the number of (high-quality) publications (as a number of empirical studies have shown). Boyer (1990), for example, asked faculty members what criteria they considered to be important for the decision to receive tenure. $95 \%$ of faculty employed at research universities ( $89 \%$ of professors employed at doctorate granting universities) stated that receiving tenure without having any publication is very difficult (if not impossible). 95\% ( $91 \%$ respectively) state that the number of publications has a major influence on tenure decisions. $83 \%$ ( $73 \%$ ) consider the journal in which the paper is published to be very important for the tenure decision. In contrast, only 10\% (19\%) consider evaluations of students to be very important for tenure committees. After receiving tenure, promotion from associate to full professorship is a second career step within the US system. By comparing associate and full professors of the same age, Fishe (1998) shows that full professors have a higher average annual research output than associate professors. In addition to differences in total output, the quality of papers also varies for full and associate professors. Full professors publish a significantly higher percentage of papers in top jour- 
nals than associate professors. Furthermore, Fishe's findings indicate that quality of research matters more for the promotion from associate to full professor than for the tenure decision.

To summarize, in the German system there is a stronger emphasis on qualification measures in the screening period than in the US system. In our model, this translates into a lower $\alpha$, i.e. a lower weight of research output in the screening period, which makes investment in skills (even on the cost of trading in research output) more attractive in the German system than in the US system. ${ }^{27}$

Therefore, career publication profiles of German researchers should be relatively lower in the first period in comparison to later periods due to higher incentives to invest in skills at the beginning. In contrast, we expect the research output of US researchers to be higher in the first period than in later periods because of a concentration of incentives on shortterm research output in the screening period.

\subsection{Incentives due to output-based pay}

Unlike Germany, the US system provides output-based income incentives on top of the tournament incentives described above. A number of studies have empirically analyzed the correlation between pay and research output of US researchers. One of the main findings is that variations in income are related more closely to variations in research output the more research-oriented a researcher's department is [Ragan/Warren/Bratsberg (1999), Moore/Newman/Turnbull (1998), Swidler/Goldreyer (1998), Gomez-Mejia/Balkin (1992), Hamermesh/Johnson/Weisbrod (1982)]. Thus, professors in research universities will receive higher returns for additional effort to produce research output than professors in teaching universities. This means that incentive intensity $(\beta)$ is higher in US research universities than in US teaching universities, which, according to our model, means that professors at research universities will invest comparatively more in skills during the screening period than their colleagues at teaching universities because of higher returns

\footnotetext{
${ }^{27}$ Note that the German system has started to change rapidly since the end of the 1990 s, converging with the US system. Publications in prestigious journals have become more and more important. At the same time, the classical Habilitation has become less important and may be totally abolished in the years to come due to a new federal law. However, for the period analyzed in this paper, the Habilitation was still the dominant criterion.
} 
on investments later on. Therefore, we predict that the career publication profiles of professors at research universities are influenced by their investments in skills in the first period (making the profile less steep at the beginning in comparison to the second career stage). Contrarily, publication profiles of professors at teaching universities are influenced less by skill investments in the first period and are more focused on producing output, making the profiles comparatively steeper in the first career stage.

\section{Empirical findings on career publication profiles}

\section{The data set}

To test our implications, we collected data from 189 German researchers and 112 US researchers in economics and business economics. The data are drawn from the personal CVs of the researchers, complemented by information collected via internet search. All German professors in the data set were appointed as professor before 1999. To obtain our German sample, we searched all faculty homepages of West German business and economics departments. We crosschecked our sample with secondary data from Enders/Bornemann (2002) and Weber/Kaminski (1994). Similar to Germany, all USprofessors in the data set were granted tenure before 1999. For the US data we drew a sample of about 1' 400 faculty members and asked them by email to provide us with a CV and a list of their publications. The response rate was $7 \%$ and random cross checks of the given information indicated a high quality of response. For both samples we have a fairly representative distribution across cohorts and sub-specializations within the two fields of economics and business economics.

\section{Dependent variable}

Research output was measured by a weighted number of publications in journals and edited books. We counted publication output in three categories: articles in top journals, articles in other journals and articles in edited books. Because German researchers published only a small fraction of their research output in international journals during the 
period that we analyze (see table 3), we would miss a major part of their publications if we considered international (top) journals only. Consequently, we have to account for the importance of German journals for promotion decisions in Germany ${ }^{28}$. Not only do we have to include German journals into our analysis but we also have to identify German top journals, which for the German academic market are functionally equivalent to international top journals for the US academic market. Schlinghoff and Backes-Gellner (2002) identify four German top journals for each economics and business economics. In business economics these are: Zeitschrift für Betriebswirtschaft, Zeitschrift für betriebswirtschaftliche Forschung, Die Betriebswirtschaft and Betriebswirtschaftliche Forschung und Praxis. In economics they specify: Kyklos, Zeitschrift für die gesamte Staatswissenschaft (Journal of Institutional and Theoretical Economics), Weltwirtschaftiches Archiv and Jahrbücher für Nationalökonomie und Statistik. Citation analysis indicates that these journals are cited approximately four to eight times more often than other German journals.

To keep chances for publishing in a top journal equal for German and US researchers, we have to take into account that there are much more international (English language) journals than German journals, and that at the same time there are much more US than German researchers. Therefore, we chose the number of international top journals in a way that gives US-researchers the same chance to publish a paper in an international top journal as it gives German researchers to publish in a German top journal. The appropriate numbers of international journals are 12 in economics and 20 in business economics. Based on this fundamental decisions we classify the following journals as international top journals from preceding rankings ${ }^{29}$ : Academy of Management Journal, Academy of Management Review, Accounting Review, Administrative Science Quarterly, Harvard Business Review, International Journal of Production Research, Journal of Accountancy, Journal of Accounting \& Economics, Journal of Accounting Research, Journal of Adver-

\footnotetext{
${ }^{28}$ The importance of German journals has been changing rapidly in recent years. However, during the time span we are analyzing, they were still very important.

${ }_{29}^{29}$ Laband/Piette 1994, Diamond 1989, Williams 1987, Niemi 1988, Jobber/Simpson 1988, Hammelmann/Mazze 1973, Mabry/Sharplin 1985, Alexander/Mabry 1994, Mc Rae 1974, Tahai/Rigsby 1998, Doyle/Arthurs 1995, Gho et al (1996), Vokurka 1996. For more details see Schlinghoff 2003.
} 
tising Research, Journal of Business, Journal of Consumer Research, Journal of Finance, Journal of Financial and Quantitative Analysis, Journal of Financial Economics, Journal of Marketing, Journal of Marketing Research, Journal of Money, Credit and Banking, Management Science, Organizational Behaviour \& Human Decision Process, Journal of Political Economy, Review of Economic Studies, American Economic Review, Econometrica, Journal of Economic Literature, Quarterly Journal of Economics, Brookings Papers on Economic Activities, Bell Journal of Economics (Rand Journal of Economics), Review of Economics, Journal of Monetary Econics, Economica, and International Economics Review.

To calculate the individual publication output per year, we use a weighted publication index. Citation analyses of international journals indicate that our findings on relative citation rates of German top journals to other journals is appropriate for US journals as well. By weighting top journals with a factor eight we are at the upper bound of various quality weights and thereby strongly emphasize quality of research in our publication indicator. Thus, we multiply articles in German top journals or international top journals by eight, articles in other journals or in edited books by two for German researchers. For researchers from the US, articles in international top journals are also multiplied by eight, articles in other journals or edited books by one. To get an unbiased dependent variable for career publication profiles we use three-year averages, since single year outputs vary strongly due to specific research production cycles and varying timing issues in the publication process of different journals and books.

First descriptive analyses provide the following results for our dependent variable. US researchers publish, on average, 0,082 articles in top journals, 0,49 articles in other journals and 0,21 articles in edited books per year (cf. table 3 ). 
Table 3: Average publication output per year

\begin{tabular}{lrrrrrrr}
\hline & GTJ & GOJ & GP & ITJ & IOJ & IP & PUB \\
\hline German researchers & 0,1091 & 0,4379 & 0,6430 & 0,0064 & 0,1028 & 0,1149 & 1,4141 \\
& $7,7 \%$ & $31,0 \%$ & $45,5 \%$ & $0,5 \%$ & $7,3 \%$ & $8,1 \%$ & $100 \%$ \\
US researchers & & & & 0,0818 & 0,4925 & 0,2091 & 0,781 \\
& & & & $10,4 \%$ & $62,8 \%$ & $26,7 \%$ & $100 \%$ \\
\hline
\end{tabular}

First row indicates number of publications.

GTJ: German top journals. GOJ: other German journals. GP: German proceedings. ITJ: International top journals.

IOJ: other international journals. IP: International proceedings.

PUB: total publication output

Second row indicates the share of the category in the total publication output.

If we compare these results with those for German researchers and only look at publications in international journals, the dominance of US researchers in international top journals is obvious. German researchers published on average only 0,006 articles in international top journals, and 0,1028 in other international journals. However, if we add publications in national journals, we find nearly the same average publication output for German and US researchers in their respective journal markets. In total, German researchers produce 0,115 articles in top journals and 0,541 articles in other journals. ${ }^{30}$

As a dependent variable in our regression analysis we use an individually standardized publication indicator (OUTPUT $\mathrm{t}, \mathrm{i})$. We use the standardized output because in order to test our hypotheses we are only interested in the shape of the lifecycle publication profile but not in the absolute level of a researcher's lifecycle publication output ( $\mathrm{t}$ is measured in years after finishing the $\mathrm{PhD}$ ). Another reason for standardizing is that overall research output is not only influenced by individual effort or skills but also by his or her field of specialization or by other unobserved heterogeneity in a researcher's productivity. By standardizing each individual researcher's publication output to zero mean and unity variance we account for exogenous differences in individual research output. ${ }^{31}$ Thus, OUTPUT $t_{t, i}$ represents the output of individual $i$ at time $t$ compared to his or her own average over his or her whole career. If OUTPUT $\mathrm{T}_{\mathrm{t}, \mathrm{i}}$ is greater than zero, a researcher pro-

\footnotetext{
${ }^{30}$ In addition, German researchers publish 0,658 articles in edited books.

${ }^{31}$ Alternatively, we could estimate first differences or fixed effects, which are very similar to standardization. However, first differences and fixed effects estimate the absolute variation in the dependent variable. Since our model predicts only relative variations, we prefer to use the individually standardized publication output. Furthermore, individual standardization enables us to compare publication profiles of German and US researchers without having to answer questions on the relative value of articles in German vs. international top journals.
} 
duces more at the time $t$ than his or her average et vice versa. We additionally analyze the influence of our explanatory variables on the weighted, quality-adjusted research output OUTPUTWEIGH t,i $_{\text {. }}$

\section{Explanatory Variables}

The most important explanatory variables, according to our model, are the various career steps in Germany and the US. On average, the first career step (screening period) in the US lasts 5 to 6 years (i.e. time from finishing a $\mathrm{PhD}$ to receiving tenure). ${ }^{32}$ Time to tenure has increased in the last decades. Researchers, for example, who were granted tenure before 1980, received their tenured position 0,8 years faster than researchers who were granted tenure after 1980. The second career step, i.e. promotion to full professor, takes again six or more years. In addition to these major career steps in rank, we observe a substantial number of horizontal career steps. On the level of assistant professor, 21 researchers reported that they changed their university. After receiving tenure, 32 professors reported that they were offered the option to change their university.

\section{Table 4: Time to promotions}

\begin{tabular}{llll}
\hline & & Average time spent between & \\
US & PhD & Assistant \\
Tenure & Associate \\
& Assistant & 5,14 & Full \\
\hline Research I & 0,43 & 5,80 & 4,93 \\
Research II & 0,62 & 4,00 & 6,31 \\
Doctorate I & $-0,32$ & 7,40 & 7,29 \\
Doctorate II & 0,31 & 5,95 & 6,00 \\
College & 0,26 & 5,63 & 7,18 \\
Average & 0,42 & & 6,05 \\
& & "Habilitation" & First App. \\
Germany & Doctorate & First App. & Re-app. \\
\hline All universities & "Habilitation" & 1,37 & 6,00 \\
\hline Source: Own Calculations & &
\end{tabular}

\footnotetext{
${ }^{32}$ See table 4 for detailed times spent on each position.
} 
The first career step (screening period) in Germany, i.e. the time from finishing the doctoral degree to finishing the Habilitation, lasts approximately six years, too. Further career steps are outside job offers (calls) from other universities. About two thirds of all professors receive at least one more job offer, and more than one third receive at least two. On average, German researchers are re-appointed about twice during their career. The average time from the first professorship to the first outside job offer is six years and to the second outside job offer is another five years.

If we compare the length of the different career steps, we find that the first career step (screening period) and the next career step period require approximately the same time in the US and in the German university system, despite the substantial differences in institutional details that we observe in the two countries.

Figure 2: Graphical representation of the regression model

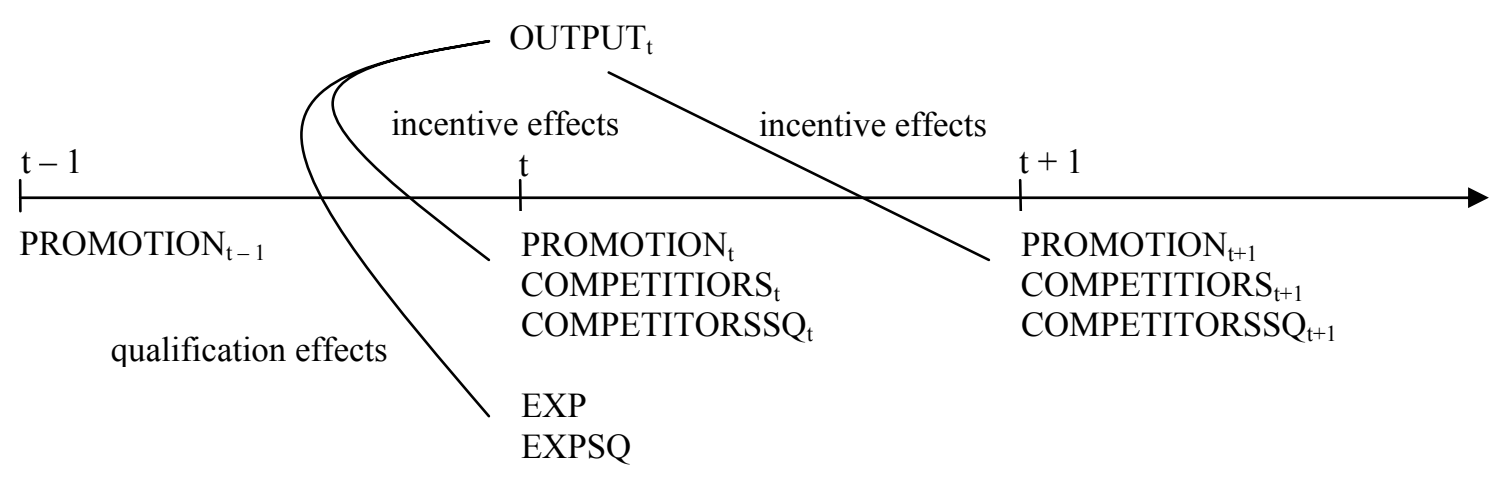

\section{Results}

To test our implications we estimate separate linear regression models for US and German researchers with OUTPUT $\mathrm{t}_{\mathrm{t}, \mathrm{i}}$ as the dependent variable (see figure 2) and the various career steps (promotions) as explanatory variables. 
PROMOTION $_{\mathrm{t}, \mathrm{i}}$ represents a career step for individual $\mathrm{i}$ at time t. For US researchers we distinguish between promotion to a tenured position (TEN), promotions to full professor (FULL) and horizontal career steps (same position, other university) on the assistant (SOASSI), associate (SO-ASSO) and full professor level (SO-FULL). For German researchers, we identify first appointments to a professorship (FIRST_APP) and re-appointments (RE_APP).

PROMOTION $_{t+1, \mathrm{i}}$ represents a promotion in the period after the actual publication output, while PROMOTION $\mathrm{t}-1, \mathrm{i}$ represents a promotion in the period before the actual publication output.

According to our model, we expect relative publication output of researcher i at time $t$ to be higher if a researcher is on the market for promotions in the following period (PROMOTION $_{t+1, i}=1$ ), so there is an incentive to work hard on research output in the previous period. But we do not expect positive career incentives right after a promotion has taken place, so research output of researcher i after a promotion $\left(\right.$ PROMOTION $\left._{t-1}=1\right)$ should not exceed his/her average level of productivity. If at all, research output after promotion should be lower due to a loss of career incentives. ${ }^{33}$

In addition to these career events, we are able to incorporate the number of jobs in the academic labor market for German researchers, which can be used as an indicator for the number of contestants in a given promotion tournament. The variables COMPETI-

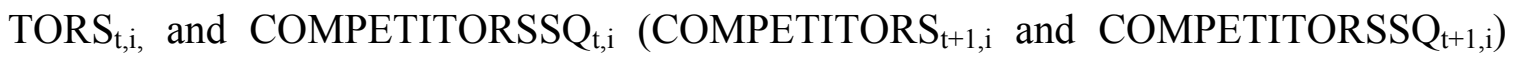
represent the labor market chances of German junior researchers measured by the ratio of the number of potential candidates (researchers who plan to finish their Habilitation within the next three years) to the number of vacant positions (number of expected job openings within the next three years). These data are provided by Borchert and Gülicher $(1979,1982,1985,1988,1991,1994)$ for three year periods and for different specialities. The variables EXP and EXPSQ represent the researcher's (squared) total job experience in years. RESEXP and RESEXPSQ are interaction terms between EXP (EXPSQ) and a dummy variable indicating whether the academic is employed by a research university

\footnotetext{
${ }^{33}$ Since in Germany a newly appointed professor has to establish her new chair there is usually a short term increase in teaching and administrative workload. Therefore, a decrease of research output below the average level is very likely in the first years after receiving tenure.
} 
(as opposed to a teaching university). By adding a linear time trend $t$ to the regression, we can also control for a general growth in the journal market.

table 5 around here

Table 5 summarizes standardized regression coefficients for the US and the German sample, respectively. All implications regarding the promotion variables are borne out in the data. Research output is significantly higher in the period preceding a promotion (positive sign of PROMOTION $\mathrm{t}_{\mathrm{t} 1 \mathrm{i}}$ ). Furthermore, as expected, research output is not higher, but on an average level (or even below average level) in the period following a promotion event (model I, US and Germany).

If we split promotions into tenure decision and promotion to full professor for US researchers (model II, US), we find that both types of promotions have almost the same impact on the weighted publication output of US researchers. We observe a significantly higher research output in the time period preceding the tenure decision, as well as in the time period before the promotion to full professor. Again, as expected, research output is not above average in the time period after the tenure decision was taken, respectively after the promotion to full professor has been granted since the incentive effect has then disappeared.

If we split promotions into first appointments and re-appointments for German professors (model II, Germany), we find some differences to US researchers. First appointments have the same effects as the tenure decision in the US. Publication output is above average in the time period preceding the first appointment and drops to average afterwards. However, we do not find any significant effects of re-appointments on research output, which is in accordance with our prediction stating that potential gains in the first round of the promotion tournament are substantially higher than in following rounds, which in turn means that first appointments should have a greater impact on research output than reappointments.

Against our expectations, our labor market variables COMPETITORS and COMPETITORSSQ are not significant. We do not find evidence for research output to increase 
with the number of contestants. However, this might as well be due to an incomplete labor market indicator (for example due to the fact that the figures are not exactly the job openings but only the number of professorships, which only translates into job openings if we take the fluctuation rate of professors into account).

If we look at the influence of experience on research output we will find a stronger influence of experience on research output for German researchers. This is due to the stronger incentives to invest in skills early in the career according to the selection criteria in the appointment process. Secondly, if we compare research and teaching oriented US universities, we expect to find a stronger influence of experience in research universities. This is due to higher returns on investments, since income depends more on research output. The regression results for German researchers meet our expectation. Job experience has a very strong significant influence on both quality-adjusted research output and number of publications. We do not find a significant influence of experience on weighted publications for US researchers in general, though. Furthermore, there is a positive though not significant correlation between the interaction of research universities ${ }^{34}$ and experience as well as publication output. For an academic employed by a research university, publication effort is influenced to a higher degree by experience. If we run the regression only for individuals who are employed by research universities, we find a significant correlation between experience and publications. By comparing standardized regression coefficients, we find that experience is more important for German researchers than for US researchers.

\section{Conclusions}

In our paper we analyze differences in individual research productivity over the lifecycle and study the impact of two different academic career systems, namely of the US and of the German system. We argue that variations in lifecycle publication patterns are driven by a combination of incentives to publish and to invest in skills, both of which depend on particular institutional characteristics of national university systems. On the one hand,

\footnotetext{
${ }^{34}$ Research universities were defined according to the Carnegie Classification scheme.
} 
publication patterns of US and German researchers are determined by the same basic mechanism: incentives to publish are provided by promotion tournaments, which result in increased publication outputs in time periods preceding a promotion and a decline in publication productivity after a promotion. On the other hand we identify some striking differences between US and German researchers, which can be related to particular differences in the design of the career paths of researchers and cause the following results: Firstly, skill acquisition is more important for German researchers in the screening period since the first promotion decision is strongly influenced by a qualification requirement, the so-called Habilitation. Secondly, German researchers lack a second major career step in comparison to US researchers, for whom the promotion to full professor is almost as important as the promotion to associate professor. Re-appointments in the German university system offer comparatively low gains and are thereby not attractive enough to induce researchers to increase their effort significantly. For US researchers the situation is different. Their research output is significantly higher prior to a promotion to full professor, indicating that this promotion provides an effective incentive to increase research output.

Since we are looking at individually standardized research output, we cannot state that one or the other career system is overall superior. If we only consider publications in international journals we find a clear predominance of US researchers. However, in the past, German economists and business economists have had a strong incentive to publish in national rather than international journals. Thus, it would be against the logic of the German system to compare the efficiency of the German and US system by just comparing the number of publications in international (English speaking) journals at least for the given time period. If, on the contrary, we compare publications in German top journals for German researchers with publications in Anglo-Saxon journals for US researchers, the gap becomes much smaller, and if we compare articles in all journals, there is no difference in research productivity at all. So it is reasonable to conclude, that researchers generally react to promotion criteria by adjusting their production and investment behavior. For the promotion to full professor in the US, and for a first appointment to professor in Germany, publications in the nation-specific top journals were most important in the 
period we studied. As a reaction, researchers who competed in these tournaments had a strong incentive to produce publications in their respective top journals, and this is exactly what they did. US researchers worked hard on publications in Anglo-Saxon journals in order to receive tenure and German researchers worked hard to publish in German journals in order to receive their first call as professor.

Over the last years, the promotion criteria of German economists and business economists have started to shift substantially towards a greater importance of publications in international journals. Therefore, we expect the publication behavior of young researchers to adjust accordingly, meaning that we should expect a significantly higher amount of German research publications in international journals in the near future (which is already quite obvious particularly in economics and becoming more and more obvious in business economics). At the same time there is a tendency towards more contingent employment arrangements in the US university system with a substantial increase in adjunct faculty from $20 \%$ part-time or temporary faculty members in 1967 to $43 \%$ in 2000 (Feldman and Turnley 2004). Since recent developments suggest that the use of adjunct faculty will continue in the future, we also expect the US publication profiles to change or rather split: traditional tenure track faculty are remaining with the old pattern, and the increasing number of adjunct faculty developing completely new focuses and patterns of productivity profiles depending on the incentives set in the new types of contracts.

\section{References}

Adams, Robert (2002): Trends in American and German Higher Education. Cambridge: American Academy of Arts and Sciences.

Alexander, John C; Mabry, Rodney H (1994) Relative Significance of Journals, Authors, and Articles Cited in Financial Research. In: Journal of Finance 49(1994)2: 697-713.

Altman, Y., Bournois, F. (2004): The "Coconut Tree" Model of Careers: The Case of French Academia.

Baruch, Y., Peiperl, M.A. (2000): Career Management Practices: An Empirical Survey and Theoretical Implications. In: Human Resource Management 39(2000)4, 247-366.

Baruch, Yehuda, Hall, Douglas T. (2004): The Academic Career: A Model for Future Careers in Other Sectors? In: Journal of Vocational Behavior 64(2004), 241-262. 
Borchert, Manfred, Gülicher, Herbert (1979): Berufungschancen künftiger Habilitanden im Fach Wirtschaftswissenschaften. In: Wirtschaftswissenschaftliches Studium 8(1979)10, 495-498.

Borchert, Manfred, Gülicher, Herbert (1982): Berufungschancen künftiger Habilitanden im Fach Wirtschaftswissenschaften. In: Wirtschaftswissenschaftliches Studium 11(1982)9, 439-441.

Borchert, Manfred, Gülicher, Herbert (1985): Berufungschancen künftiger Habilitanden im Fach Wirtschaftswissenschaften. In: Wirtschaftswissenschaftliches Studium 14(1985)8, 427-429.

Borchert, Manfred, Gülicher, Herbert (1988): Berufungschancen künftiger Habilitanden im Fach Wirtschaftswissenschaften. In: Wirtschaftswissenschaftliches Studium 17(1988)9, 476-478.

Borchert, Manfred, Gülicher, Herbert (1991): Berufungschancen künftiger Habilitanden im Fach Wirtschaftswissenschaften. In: Wirtschaftswissenschaftliches Studium 20(1991)7, 370-374.

Borchert, Manfred, Gülicher, Herbert (1994): Berufungschancen künftiger Habilitanden im Fach Wirtschaftswissenschaften. In: Wirtschaftswissenschaftliches Studium 23(1994)7, 372-375.

Boyer, Ernest L. (1990): Scholarship Reconsidered. Princeton: Carnegie Foundation for the Advancement of Teaching.

Buchmueller, Thomas C., Dominitz, Jeff, Hansen, W. Lee (1999): Graduate Training and the Early Career Productivity of $\mathrm{PhD}$ Economists. In: Economics of Education Review 14(1999)1, 65-77.

Caplow, T., McGee, R.J. (1958): The Academic Marketplace. Garden City, NY: Anchor Books.

Cole, Stephen (1979): Age and Scientific Performance. In: American Journal of Sociology 84(1979)4, 958-977.

Coupé, Tom (2004): What Do We Know About Ourselves? On the Economics of Economics. In: Kyklos 57(2004)2: 197-216.

Coupé, Tom, Smeets, Valerie, Warzynski, Frederic (2003): Incentives in Economics Departments I: Dynamic Incentives of Top Economists. Brussels: mimeo.

Danesy, Frank C. (1994): Higher Education Credentials: A Guide to Educational Systems in Europe and North America. New York: Wiley.

Dennis, Wayne (1956): Age and Productivity among Scientists. In: Science 123(1956)27 April, 724-725.

Diamond, Arthur (1989) The Core Journals of Economics. In: Current Contents 21(1989): 4-11.

Diamond, Arthur M. (1984): An Economic Model of the Life-Cycle Research Productivity of Scientists. In: Scientometrics 6(1984)3, 189-196.

Diamond, Arthur M. (1987): An Optimal Control Model of the Life-Cycle Research Productivity of Scientists. In: Scientometrics 11(1987)3-4, 251-253.

Doyle, J.R., Arthurs, A.J. (1995) Judging the Quality of Research in Business Schools: The UK as a Case Study. In: Omega, International Journal of Management Sciences 23(1995)3: 257270.

Ehlert, Holger, Cordier, Heidi (2002): The Transition from Higher Education to the Labor Market. International Perspectives and Challenges. Frankfurt: Lang.

Enders, Jürgen, Bornmann, Lutz (2002): Karriere mit Doktortitel? Ausbildung, Berufsverlauf und Berufserfolg von Promovierten. Frankfurt, New York: Campus. 
Feldman, D.C., Turnley, W.H. (2004): Contingent Employment in Academic Careers: Relative Deprivation among Adjunct Faculty. In: Journal of Vocational Behavior 64(2004), 284-307.

Fishe, Raymond P.H. (1998): What Are the Research Standards for Full Professor of Finance? In: Journal of Finance 53(1998)3, 1053-1079.

Gho, C.H., Holsapple, C.W., Johnson, L.E., Tanner, J. (1996) An Empirical Assessment of Influences on POM Research. In: Omega, International Journal of Management Science 24(1996)3: 337-345.

Gibbs, Michael (2001): Promotions and Incentives. Chicago: mimeo.

Gomez-Mejia, Luis R., Balkin, David B. (1992): Determinants of Faculty Pay: An Agency Theory Perspective. In: Academy of Management Journal 35(1992)5, 921-955.

Goodwin, Thomas H., Sauer, Raymond D. (1995): Life Cycle Productivity in Academic Research: Evidence from Cumulative Publication Histories of Academic Economists. In: Southern Economic Journal 61(1995)3, 728-743.

Hamermesh, Daniel S., Johnson, George E., Weisbrod, Burton A. (1982): Scholarship, Citations and Salaries: Economic Rewards in Economics. In: Southern Economic Journal 49(1982)2, 472-481.

Hammelmann, Paul M, Mazze, Edward M. (1973) Cross-referencing between AMA Journals and other Publications. In: Journal of Marketing Research 10(1973)2: 215-218.

Hartmer, Michael (1996): Besoldung und Versorgung des wissenschaftlichen Personals. In: Flämig, Christian (Hrsg.): Handbuch des Wissenschaftsrechts. Heidelberg u.a.: Springer, 509544.

Hutchinson, E. Bruce, Zivney, Terry L. (1995): The Publication Profile of Economists. In: Journal of Economic Education 26(1995)1, 59-79.

Jobber, David, Simpson, Paul (1988) A Citation Analysis of Selected Marketing Journals. In: International Journal of Marketing Research 5(1988)2: 137-142.

Kenny, Lawrence W., Studley, Roger E. (1995): Economists' Salaries and Lifetime Productivity. In: Southern Economic Journal 62(1995)2, 382-393.

Laband, David N., Piette, Michael J. (1994) The Relative Impacts of Economics Journals: 19701990. In: Journal of Economic Literature 32(1994)2: 640-666.

Lazear, Edward P., Rosen, Sherwin (1981): Rank-Order Tournaments as Optimal Labor Contracts. In: Journal of Political Economy 89(1981)5, 841-864.

Lehman, Harvey C. (1953): Age and Achievement. Princeton: Princeton University Press.

Lehman, Harvey C. (1958): The Chemist's Most Creative Years. In: Science 127(1958)23 Mai, 1213-1222.

Lehman, Harvey C. (1966): The Psychologists Most Creative Years. In: American Psychologists 21(1966), 363-369.

Levin, Sharon G., Stephan, Paula E. (1991): Research Productivity over the Life Cycle: Evidence for Academic Scientists. In: American Economic Review 81(1991)1, 114-132.

Mabry, Rodney, Sharplin, Arthur D. (1985) The Relative Importance of Journals Used in Finance Research. In: Journal of Financial Research 8(1985)4: 287-296. 
Mahoney, Christine B., Ready, Kathryn J. (1997): Tenure: The Process of Attaining Long-Term Employment in Academia. In: Wallace, Joe, Dalzell, Tom, Delany, Bernard (Hrsg.): Continuity and Change in the Employment Relationship. Dublin: Oak Tree Press, 211-229.

Mc Rae, Thomas W. (1974) A Citational Analysis of Accounting Information Network. In: Journal of Accounting Research 12(1974)1: 80-92.

McDowell, John M. (1982): Obsolescence of Knowledge and Career Publication Profiles: Some Evidence of Differences among Fields in Costs of Interrupted Careers. In: American Economic Review 72(1982)4, 752-768.

Moore, William J., Newman, Robert J., Turnbull, Geoffrey K. (1998): Do Academic Salaries Decline with Seniority? In: Journal of Labor Economics 16(1998)2, 352-366.

Niemi, Albert W. (1988) Research Productivity of American Business Schools. In: Review of Business and Economic Research 23(1988)2: 1-16.

Oster, Sharon M., Hamermesh, Daniel S. (1998): Aging and Productivity among Economists. In: Review of Economics and Statistics 80(1998)1, 154-156.

Peiperl, M.A., Baruch, Y. (1997): Back to Square Zero: The Post-Corporate Career. Organizational Dynamics 25(1997)4, 7-22.

Ragan, James F., Warren, John T., Bratsberg, Bernt (1999): How Similar Are Pay Structures in 'Similar' Departments of Economics? In: Economics of Education Review 18(1999)3, 347360.

Schlinghoff, Axel (2002): Hiring and Promotion Strategies of German and American Business and Economics Departments. Köln: mimeo.

Schlinghoff, Axel (2003) Karriereanreize für deutsche und amerikanische Hochschullehrer - eine personalökonomische und empirische Analyse des langfristigen Forschungsoutputs. Köln: mimeo 2003.

Schlinghoff, Axel, Backes-Gellner, Uschi (2002): Publikationsindikatoren und die Stabilität von Zeitschriftenrankings. In: Zeitschrift für betriebswirtschaftliche Forschung 54 (2002)4, 343362.

Stryker, R. (2003): Mind the Gap: Law, Institutional Analysis and Socio-Economics. In: SocioEconomic Review 1(2003)3, 335-367.

Swidler, Steve, Goldreyer, Elizabeth (1998): The Value of a Finance Journal Publication. In: The Journal of Finance 53(1998)1, 351-363.

Tahai, Alireza, Rigsby, John T. (1998) Information Processing Using Citations to Investigate Journal Influence in Accounting. In: Information Processing \& Management 34(1998)2/3: 341-359.

Taylor, P.G. (1999): Making Sense of Academic Life: Academics, Universities and Change. Buckingham: Open University Press.

Trow, M. (1993): Federalism in American Higher Education. In: Levine, A (ed) Higher Learning in America: 1980-2000. Baltimore: Johns Hopkins Press: 39-66.

Weber, Jürgen, Kaminski, Arndt (1994): Zum Promotionsverhalten in der deutschsprachigen Betriebswirtschaftslehre. Vallendar: mimeo. 
Weisbrod, Burton A. (1964): External Benefits of Public Education: An Economic Analysis. Princeton, N.J.: Princeton University, Industrial Relations Section.

Vokurka, Robert J. (1996) The Relative Importance of Journals Used in Operations Management Research - A Citation Analysis. In: Journal of Operations Management 14(1996): 345-355.

Williams, William W. (1987) Institutional Propensities to Publish in Academic Journals of Business Administration. In: Quarterly Review of Economics and Business 27(1987)1: 77-94. 
Table 5: Promotions and research output

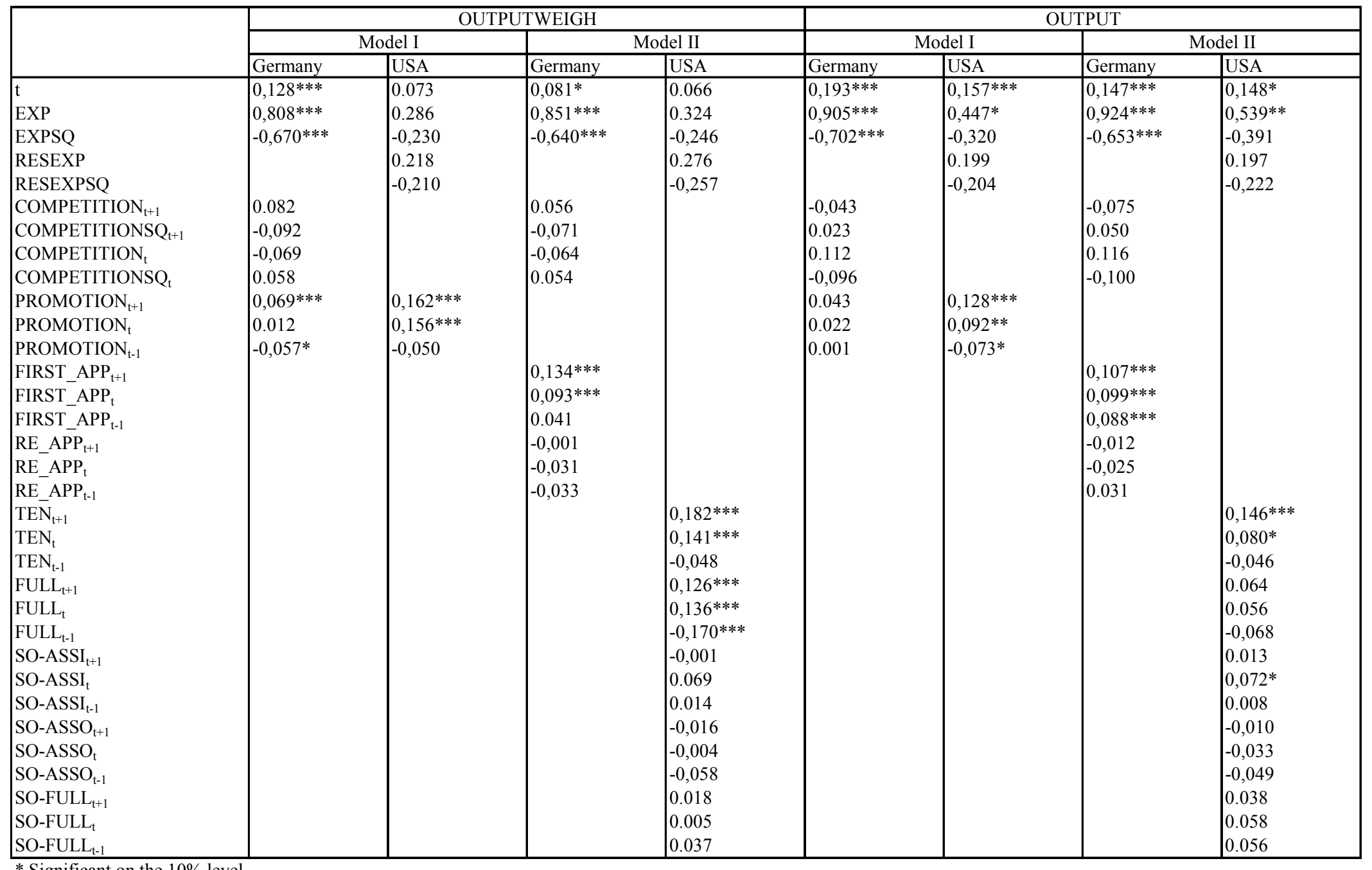

* Significant on the $10 \%$ level

** Significant on the $5 \%$ level

*** Significant on the $1 \%$ level 